\title{
Anthropometric Indices: Good Predictor of Diabetes Mellitus Type-2
}

\author{
Sanjeev Dhakal ${ }^{1}$, Uday N Singh ${ }^{2}$, Subodh Kumar ${ }^{3}$ \\ ${ }^{1}$ Associate Professor, Department of Biochemistry, Sikkim Manipal Institute Of Medical Sciences, Gangtok, Sikkim(India) \\ ${ }^{2}$ Professor, Department of Biochemistry, Major S.D. Singh Medical college \&Hospital,Farrukhabad,U.P.(India) \\ ${ }^{3}$ Assistant Professor, Department of Biochemistry, Haryana Institute Of Medical Sciences,Karnal,Haryana(India)
}

\begin{abstract}
Anthropometric indices especially, body mass index (BMI) and waist-hip ratio(WHR) are important in the development of Diabetes Mellitus(DM) type-2. BMI is the marker of overweight and obesity whereas WHR is the marker of fat content in upper and lower part of human body. Increased BMI and WHR leads to insulin insensitivity also known as insulin resistance which results into diabetes mellitus type-2 due to hyperglycemia. Most of the diabetcs have impaired BMI and WHR which have been found closely correlated with blood sugar levels in DM type-2 patients. They can predict the onset of DM type-2 in future in persons having abnormally increased BMI and WHR.
\end{abstract}

Keywords: BMI, WHR, Diabetes Mellitus, type-2

\section{Introduction}

Diabetes mellitus is the commonest global metabolic disease at present and its prevalence is gradually increasing day by day all over the world, especially in developing nations. According to World Health Organisation report 2005, the no. of diabetic people was around 171 million and would increase to 366 million by year $2030 .^{[1]}$

The maximum burden of diabetic society is particularly contributed by diabetes mellitus type-2. It accounts for about $90 \%$ cases of diabetes. ${ }^{[2]}$ and it is assumed that diabetes type -2 will alone affect 250 million people by year 2010 and 300 million people by year $2025 .^{[3,4]}$

India has been declared as the Diabetc Capital of the world. ${ }^{5}$ In India alone, 31.7 million people were affected in year 2000 and is expected to reach 79 million by the year $2030 .^{[1]}$ Diabetes is a chronic metabolic disease characterized by high blood sugar levels resulting from defects in insulin secretion, insulin action, or both which prevent the body to utilize glucose completely or partially. ${ }^{[6]}$

Diabetes was previously considered an elderly disease but now-a-days, its prevalence is gradually increasing in youth and middle aged people. ${ }^{[2]}$ it is perhaps due to change in life style and food style of human beings. Obesity, particularly visceral or central as evidenced by the waist -hip ratio is very common in diabetes mellitus type-2. ${ }^{[7]}$ The waist -hip ratio is used as an indirect measure of upper and lower body fat content..

It is a multifactorial disease in which hereditary predisposition alone is not only responsible but several factors such as ethnic background, diet, physical work, obesity, ageing and stress have been shown to affect the development of diabetes. People having little physical activity and energy rich foods are most likely to develop overweight and obesity. Excess deposition of fat in body as seen in obesity leads to the reduced sensitivity of body tissues to the action of insulin also known as "INSULIN RESISTANCE " in the utilization of glucose. ${ }^{[8,9]}$ lack of physical activity and obesity predisposes to the development of diabetes in the later stage of a person's life. ${ }^{[10]}$

Anthropometry indices,particularly body mass index(BMI) and waist hip ratio( WHR) are mainly used to measure obesity in persons. WHR is closely linked with BMI and is appropriate index of intra abdominal fat mass and total body mass. Obesity ,particularly visceral or central as evidenced by the waist hip ratio(WHR) is very common in Diabetes type-2. ${ }^{[7]}$ There is an increased risk of metabolic complications for men with WHR. $\geq 102 \mathrm{~cm}$ and women with WHR $\geq 88 \mathrm{~cm}$. A higher WHR reflects a greator proportion of abdominal fat with greater risk for hyperinsulinemia, insulin resistance, diabetes type 2, endometrial cancer, hypercholesterolemia, hypertension and atherosclerosis. ${ }^{[11]}$ So the present study is aimed to evaluate BMI and WHR as predictor of diabetes type -2 .

\section{Methodology}

For the present study, 100 diabetic type -2 males and 100 normal males were randomly selected between age group 35 to 45 years of life in medicine O.P.D. OF Major S D Singh Medical College and Hospital,Farrukhabad. The purpose of the study was explained and they gave their consent for the work.BMI and WHR value were calculated by measuring height, weight, waist and hip circumference of all study subjects(both diabetic and normal) in standing standing position wearing light clothing and no shoes .Body weight was measured by digital weighing machine. Height was measured with a portable sicca stadiometer. .Body mass index (BMI) was calculated as the ratio of body weight $(\mathrm{kg})$ per height square $\left(\mathrm{m}^{2}\right)$. Waist circumference was measured at the level of umbilicus and hip circumference was measured at the widest circumference around the buttocks, waist hip ratio(WHR) was calculated from these circumferences.In addition to ,their fasting and post- prandial blood sugar values were also collected from clinical Biochemistry lab. 


\section{International Journal of Science and Research (IJSR)}

ISSN (Online): 2319-7064

Index Copernicus Value (2013): 6.14 | Impact Factor (2014): 5.611

\section{Result and Discussion}

The different parameters of anthropometry in the study group had been shown in table no. 1. In addition ,their correlation were also studied with fasting and post prandial blood sugars levels of the study groups as shown in table no .2. All anthropometric indices except height shows significant difference between diabetic and control groups. Diabetic person's body weights were quite higher than control subjects.

Table 1: Distribution of anthropometric indices among male diabetic type- 2 and male controls

\begin{tabular}{|c|c|c|}
\hline Variables & $\begin{array}{c}\text { Diabetic } \\
\text { subjects }(n=100)\end{array}$ & $\begin{array}{c}\text { Control } \\
\text { subjects }(n=100)\end{array}$ \\
\hline Height (Mean $\pm \mathrm{SD})$ in meter & $1.625 \pm 0.04$ & $1.627 \pm 0.035$ \\
\hline Weight (Mean \pm SD) in kg & $89.2 \pm 20.9$ & $70.1 \pm 12.92$ \\
\hline BMI $\left(\mathrm{kg} / \mathrm{m}^{2}\right)$ & & \\
$\leq 18.5$ & - & 13 \\
$18.2-25$ & 30 & 67 \\
$25-30$ & 40 & 17 \\
$>30$ & 30 & 3 \\
$($ Mean $\pm \mathrm{SD})$ & $30.0 \pm 11.1$ & $24.8 \pm 6.0$ \\
\hline $\mathrm{WHR}$ & & \\
$\leq 0.9$ & 10 & 50 \\
$0.91-1$ & 50 & 25 \\
$\geq 1$ & 40 & 25 \\
$($ Mean $\pm \mathrm{SD})$ & $0.99 \pm 0.35$ & $0.91 \pm 0.31$ \\
\hline
\end{tabular}

Most of the diabetic persons (about 70\%) fell under preobese or obese category as compared to controls having $20 \%$ pre-obese or obese category. Jimaima et al(2001) also reported that $63 \%$ of the diabetics had BMI $\geq 30 \mathrm{~kg} / \mathrm{m}^{2} .^{[2},{ }^{12]}$ This observation was in consistent with previous findings. ${ }^{[13,14]}$ Regarding waist hip ratio in the study groups, $50 \%$ of the diabetics fell under moderately impaired WHR and $40 \%$ of the diabetics had severely impaired WHR as compared to the control groups(table no.1 ) i.e. $90 \%$ of the diabetcs had impaired WHR and $10 \%$ of the diabetics had normal WHR as compared to control groups having 50\% normal WHR showing that gradual increase in WHR threatens the onset of diabetes type -2 . Diabetes people were most likely to had impaired WHR. Similar result was also found by Despress(1993) who found that, in particular ,abdominal obesity has been shown as a significant risk factor for the development of diabetes type $-2 .^{[15]}$

WHR (waist hip ratio) is the important anthropometric indice to indicate central obesity and distribution of fat in the body. Increased WHR leads to the insensitivity of insulin receptors also known as insulin resistance which results into the development of diabetes. ${ }^{[8,9]}$ In the study, diabetics type -2 had significantly higher WHR ratio than controls which were in consistent with previous findings. ${ }^{[16,17,18]}$
Table 2: Correlation of coefficient between anthropometric indices and diabetes type- 2

$\mathrm{NS}=$ Non-Significant $*$ - significant at 5\%,**- significant at $10 \%$

\begin{tabular}{|c|c|c|}
\hline \multirow{2}{*}{$\begin{array}{c}\text { Anthropometric } \\
\text { indices }\end{array}$} & \multicolumn{2}{|c|}{ Blood sugar level (mg/dl) } \\
\cline { 2 - 3 } & Fasting & Post-prandial \\
\hline Total body weight & 0.458 & $0.319^{*}$ \\
\hline BMI & $0.567^{* *}$ & $0.313^{*}$ \\
\hline WHR & $0.647^{* *}$ & $0.129(\mathrm{NS})$ \\
\hline
\end{tabular}

Anthropometric indices .especially BMI and WHR are positively and significantly correlated with blood sugar levels of the diabetics (Table no.2). Need et.al. (2005) and Nabi et al (2002) also observed in their study that fasting sugar levels were positively and significantly correlated with BMI. ${ }^{[19,20]}$ These findings supported the evidence that BMI and WHR posed a higher risk for the diabetes type- 2 .

In the study, most of the diabetes were fallen under overweight $(40 \%)$ or obese category $(30 \%)$. whereas $90 \%$ of diabetics were seen in moderately or severely impaired WHR i.e. WHR $>1$. Thus the study showed that BMI AND WHR were strongly associated with an increased risk of developing diabetes type -2 . and could warn against impending diabetes in future.

\section{Conclusion}

The study showed that anthropometric indices i.e. BMI and WHR could predict the onset of diabetes type -2 or the susceptibility of persons to diabetes type- 2 in near future.

\section{References}

[1] Sandhu HS,Koley S,Sandhu KS.study of correlation between lipid profile and waist- hip ratio in Diabetes Mellitus.Anthropologist 2008;10(3)215-18.

[2] Chandramohan P, Mohan V. High prevalence of diabetes and metabolic syndrome among police man. JAPI NOV.2008:56:837-38.

[3] Osei K. Global epidemic of type -2 diabetes: implications for developing countries .ETHN.dis. 2003, 13[supp12]:s2102-s2106.

[4] King H. Rewers M.Global estimates for prevalence of diabetes mellitus and impaired glucose tolerance in adults. Diabetes Care. 1993; 16:157-77.

[5] Bezbaruah S. The new face of diabetes, striking the young India Today, (2003)10:14-22.

[6] ZImmet P. Epidemiology of diabetes mellitus theory and practice, .NewYork(1983); 451-468.

[7] Powers AC. Diabetes mellitus in :Harrison,s principles of internal medicine. $17^{\text {th }}$ ed. .Fauci AS ,Braunwald E, Kasper DL, Hauser SL, Longo DL, Jameson JL, et al. editors .New Delhi: Mc Graw Hill;2008p.22753002,1143 .

[8] Seppala-Lindroos A, Vehkavaara S, Hakkinen AM, et al. Fat accumulation in the liver is associated with defects in insulin suppression of glucose production and serum free fatty acids independent of obesity in normal men. J CLIN ENDROCRINOL META.2002:87:302328.

[9] Sinha R, Dufour S ,Petersen ,et al. Assessment of skeletal muscle triglyceride content by( 1) H nuclear 


\section{International Journal of Science and Research (IJSR) \\ ISSN (Online): 2319-7064}

Index Copernicus Value (2013): 6.14 | Impact Factor (2014): 5.611

magnetic resonance spectroscopy in lean and obese adolescent relationship to insulin sensitivity ,total body fat and central adiposity.Diabetes;2002:51:1022-7.

[10] Raghuram T.C.Diet and diabetes mellitus .In text book of human nutrition. Bamji, MS., ,Rao,NP. and Reddy,V. Oxford and IBH publishing Co. Pvt. Ltd. ,New Delhi. (1998)

[11] Guidlines on Overweight and Obesity :electronic text book. Clinical Guidelines on identification ,evaluation and treatment of overweight \& obesity in adults: The evidence report $; 1998$.

[12] Jimaima V Lako and Van Chuyen Nguyen .Dietary pattern and risk factors of diabetes mellitus among urban indigenous women in Fijji. Asia Pacific $\mathrm{J}$ Clin Nutr(2001)10(3):188-193.

[13] Abbasi F, Brown BWB, Lamenbola C, McLaughlin T, Reaven GM. Clinical study :Obesity ,Diabetes, and Heart Diseasse .Relationship between obesity ,insulin resistance and coronary heart disease risk. J Am Coll Of Cardiol.2002;40:937-94.

[14] Hettiheva LM, dharmastri LP, Ariyaratne CD, Jayasinghe SS, Weerarathna, TP ,Kotapola IG. Significance correlation between BMI/BMW with insulin resistance by McAuley, HOMA and QUICKI indices After 3 months of Pioglitazone in diabetes population. International Journal of Diabetes in Developing Countries.2007;27(3)87-92.

[15]Despress JP. Abdominal obesity as important component of insulin resistance syndrome .Nutrition(1993):9:452-459.

[16] Arora N,Koley S,Gupta s,Sandhu JS.A study on lipid profile and body fat in patients with diabetes mellitus. Anthropologis 2007;9(4):295-298.

[17] Qlao Q, Nyamdorj R. Is the association of type2 diabetes with waist circumference or waist to hip ratio stronger than that with body madd index?J Clin Nutr.2010 Nov;64(11);1377.

[18] Vazquez G., Duval S, Jacobs DR Jr, Silventoinen K. Comparison of body mass indices,waist circumferences, and waist -hip ratio in predicting incidence of diabetes.a metaanalysis,Epidemiol Rev.2007;29:115-28.

[19] Nabi, N, Popa AR, and Babes A. The study of the relationship between the abdominal obesity ,the impaired glucose tolerance and hyperinsulinemia in a Bihor country population group.(2002)..Endocrine Abstract, 4P 21.

[20]Need Allan G, Q Loughlin, Peter D, Horowitz Michael and Nocardia Christopher, B.E. Relationship between fasting serum glucose, age, BMI and serum 25 -hydroxy vitamin D in postmenopausaL women.(2001)Clinical Endocrinology.62(6):738-741. 